\title{
O APARATO LEGAL BRASILEIRO E A TEMÁTICA DA PARTICIPAÇÃO EM ÁREAS PROTEGIDAS
}

\author{
Renata de Souza ${ }^{1}$
}

Tânia Maria de Freitas Barros Maciel $^{2}$

\section{RESUMO}

Estratégias políticas vinculadas à inclusão da sociedade nas tomadas de decisão são cada vez mais discutidas e adotadas pelo Estado brasileiro. O debate relacionado ao tema abarca questões benéficas tanto para o Estado quanto para a população, pois as práticas participativas podem ser de grande valia para o Estado - visto que este deixa de ser o único responsável pelas políticas sociais - e para a população - pois, a ampliação da participação em instâncias políticas e decisórias é de relevância para garantir autonomia, empoderamento, diminuição das injustiças, além de gerar benefícios sociais e econômicos. Quando se trata de áreas protegidas, muitos autores são categóricos em afirmar que a incorporação de práticas participativas nas estratégias de gestão dessas áreas é de grande importância não apenas para a população, como também para efetivar e consolidar a política de proteção e conservação da natureza. Portanto, devido à relevância da questão da participação para a conservação de áreas protegidas o presente trabalho vislumbra analisar o aparato legal brasileiro relacionado às áreas protegidas, no intuito de compreender como a temática da participação é inserida nesses documentos.

Palavras chave: Inclusão social; unidades de conservação; legislação ambiental.

\begin{abstract}
Strategies policies related to the inclusion of society in decision-making are increasingly discussed and adopted by the Brazilian State. The topic related to the debate covers issues beneficial both for the state and for the people, because the participatory practices can be of great value to the state - as this is no longer solely responsible for social politics - and the public - because, the expansion of participation in political and decisionmaking is relevant to ensure autonomy, empowerment, reduction of injustice, and social and economic benefits. When it comes to protected areas, many authors claim that the incorporation of participatory practices in the areas of these management strategies is of great importance not only for the population but also to effect and consolidate protection politics and nature conservation. Therefore, due to the relevance of the issue of participation for the conservation of protected areas the present work presents analyze the Brazilian law enforcement related to protected areas in order to understand how the issue of participation is included in these documents.
\end{abstract}

Keywords: Social inclusion; protected areas; environmental laws.

\footnotetext{
${ }^{1}$ Universidade Federal do Rio de Janeiro. E-mail: resouza_1985@yahoo.com.br

${ }^{2}$ Universidade Federal do Rio de Janeiro. E-mail: taniabm@gmail.com
} 


\section{INTRODUÇÃO}

$\mathrm{O}$ conceito de participação é antigo e remete às sociedades Grega e Romana. No entanto, de maneira distinta ao entendimento atual que formula a participação como direito de todos, nessas sociedades o direito de participar da vida pública era privilégio de apenas algumas pessoas pertencentes às classes mais abastadas. Para os gregos e romanos, a participação era exercida como extensão da liberdade, entendida como o direito de participar da vida pública e dos processos políticos (COMPARATO, 1989).

Apesar da manifestação de gregos e romanos como os primeiros a implementar práticas participativas em suas sociedades, o estudo científico dessa temática, de acordo com Gohn (2011), desponta a partir das ideias de Jean-Jacques Rosseau. Para esse autor, a participação é indispensável para a formação de um governo coeso e harmônico com os interesses da população.

Atualmente o conceito de participação vem sendo largamente desenvolvido e debatido. A retórica acerca dos benefícios dessa prática para população, governos e para a sustentação de políticas públicas é amplamente discutida, pois participar significa proporcionar autonomia para a população, rompe com a propensão do estado de instituir decisões arbitrárias, possibilita aos governos obter auxílio da população e fundamenta-se na capacidade do cidadão de tomar decisões relativas à sua comunidade e seu bem estar.

No entanto, o conceito atual de participação não é homogêneo, seu entendimento é difuso e dependente de valores políticos, ideológicos, culturais, econômicos, ambientais e de posição social (DEMO; 1988; GOHN, 2011; LOUREIRO, 2012). A falta de coesão sobre o conceito de participação, de acordo com Tuler \& Webler (1999), abre brecha para uma variedade de interpretações e práticas que podem gerar a manipulação desse processo.

O termo participação é aproveitado por governos e grupos hegemônicos para simular a inclusão social de classes mais marginalizadas. No entanto, na prática o que ocorre é a manutenção da dominação, pois o papel designado aos cidadãos é de ser informados e conscientizados, porém evita-se que a participação proporcione aos indivíduos a prerrogativa de participar das decisões (DEMO, 1988; LOUREIRO, 2012).

Nesse sentido, a participação tutelada por agentes hegemônicos faz a população acreditar que está ativamente engajada e intensamente participante do processo democrático, quando na realidade estão apenas reproduzindo os ideais das elites dominantes.

Portanto, a discussão a respeito da participação é complexa e agrega inúmeras formas de entendimento dessa prática, desde manifestações bem intencionadas de legitimar e instaurar equidade de decisão política, social, econômica, até a emergência de projetos participativos impostos de cima para baixo, com o intuito de apenas minimizar os conflitos e de manter a posição privilegiada dos governos e de determinados grupos.

Muitos são os autores que definem das mais diversas formas o conceito de participação. Para o delineamento do presente trabalho realizou-se um compendio das definições formuladas por Demo (1988) e Loureiro (2004, 2012). Nesse sentido, participação é vista como um processo coletivo, onde instituições de diversos tipos e indivíduos de 
diferentes grupos devem negociar de maneira que todos tenham voz, direito de opinião e principalmente de decisão. O processo participativo deve incitar a corresponsabilidade entre o poder público e a sociedade e fortalecer a democracia. A participação prima pelo acesso igualitário nas instâncias decisivas, pelo empoderamento das populações locais, pelo acesso a bens socialmente produzidos, pela superação das injustiças, pela geração de benefícios sociais e econômicos aos mais desfavorecidos e deve suscitar melhores condições de vida.

No Brasil a ideia de participação surge de maneira mais organizada na década de 1960. Nessa época a participação não era entendida como princípio para o enraizamento da democracia. O que se convencionou a denominar de participação popular tinha como foco a emancipação e melhoria da condição de vida das camadas populares, não havia preocupação de envolver a população nas decisões dos Estados e nas esferas locais (LAVALLE, 2011).

A radicalização no entendimento do conceito de participação ocorre apenas vinte anos mais tarde, na década de 80. De 1980 em diante esse conceito passa a remeter a participação da população nas decisões políticas (LAVALLE, 2011). O marco decisivo na ampliação do entendimento de participação como aprofundamento do processo democrático e de envolvimento da população nos processos decisórios ocorre a partir da promulgação da Constituição de 1988 (DAGNINO, 2002).

Nesse sentido, no Brasil, desde que a discussão a respeito da participação se ampliou nos anos 1960, até os dias de hoje, a temática vem ganhando adeptos, e diferentes formas de participação vêm crescendo no país. De acordo com Avritzer (2011), são muitas as áreas que acolhem experiências participativas, como a área da saúde, educação, habitação e ambiental. Para esse autor (op. cit.), as políticas participativas são cada vez mais definidas como estratégicas na gestão pública, e esse aumento do envolvimento social na gestão do que o autor denomina de "coisa pública" é perceptível na proliferação da instituição de conselhos gestores no século XXI.

Desse modo, a discussão relativa à participação em áreas protegidas revela-se um desdobramento dessas ponderações que, desde 1960, vem se ampliando no país. O debate a respeito da participação da sociedade em áreas protegidas é reconhecido pelo aparato legal brasileiro referente à proteção da natureza. Nesse sentido, as principais leis que instituem e que regulamentam as áreas protegidas dentro do estado brasileiro - a Lei ${ }^{\circ} 9.985$ de 18 de julho de 2000, que institui o Sistema Nacional de Unidades de Conservação (SNUC), o Decreto $\mathrm{n}^{\circ} 5.758$ de 13 de abril de 2006, que institui o Plano Estratégico Nacional de Áreas Protegidas (PNAP) e em menor grau o Código Florestal, Lei $\mathrm{n}^{\circ} 4.771$, de 15 de setembro de 1965, modificada pelas Lei $\mathrm{n}^{\circ} 7.803$, de 18 de julho de 1989 e pela Lei $\mathrm{n}^{\circ} 12.651$, de 25 de maio de 2012 - abordam em algum grau a temática da participação.

De acordo com Irving (2008), a participação da sociedade em áreas protegidas é de vital importância para efetivar a política de proteção dessas áreas, pois possibilita tornar as medidas de proteção da natureza mais eficientes. A discussão relativa à participação é de grande relevância devido à complexidade dos problemas ambientais, que requer decisões flexíveis, inovadoras, interdisciplinares e transparentes. Desse modo, é necessário que essas decisões agreguem uma diversidade de conhecimentos e valores (REED, 2008). 
De acordo com Reed (2008), a integração dos conhecimentos locais ao conhecimento científico usado nas estratégias de conservação de áreas protegidas é relevante para promover uma compreensão mais holística da complexa dinâmica ecológica e socioambiental.

A importância da participação em prol da conservação de áreas protegidas ocorre devido à sensibilização que o "fazer parte" desperta no indivíduo. De acordo com Gonh (2011) o engajamento gera um sentimento de pertencimento com relação à área em questão, fazendo com que o indivíduo estreite seu vinculo afetivo com o local, o que pode gerar maior comprometimento com os projetos de conservação da área protegida.

Entretanto, a participação em áreas protegidas não tem relevância apenas para auxiliar nas estratégias políticas de conservação dessas áreas. De acordo com autores que estudaram a temática da participação, a exemplo de Demo (1988) e Loureiro (2004, 2012), uma maior influência da comunidade de maneira igualitária nas instâncias decisórias, pode gerar o empoderamento da população local, proporcionar autonomia para os moradores, auxiliar na superação de injustiças e suscitar o fortalecimento da cultura local e gerar benefícios sociais e econômicos.

Nesse sentindo, a criação e gestão de áreas protegidas devem ser efetivadas de modo que valorize a memória e os costumes da população local, na intenção de fortalecer a autoestima e o contexto histórico de determinada região, para que o gerenciamento da área não seja efetuado de forma que se sobreponha aos interesses e a cultura local.

Após esta breve introdução pode-se perceber a importância da inserção de práticas participativas para a conservação de áreas protegidas e para a população que vive dentro e nos entornos dessas áreas. Por essa razão, o presente estudo se propôs a analisar e compreender como a legislação brasileira incorpora estratégias participativas em seus documentos.

\section{OBJETIVOS}

Com o presente trabalho objetivou-se averiguar como é inserida a temática da participação no aparato legal brasileiro referente a áreas protegidas. De modo a investigar como cada lei aborda a temática da participação, analisar quais as práticas participativas resguardadas por cada uma das leis relacionadas às áreas protegidas e relacionar com o contexto histórico/político no qual essas leis foram sancionadas.

\section{METODOLOGIA}

Como o intuito do presente trabalho consiste em buscar compreender como o envolvimento populacional, denominado por participação, é enunciado no aparato legal relativo às áreas protegidas, optou-se por realizar o processo de análise documental.

A análise documental é definida por Oliveira (2007) como sendo um método de pesquisa que recorre a fontes primárias, isto é, documentos que não receberam nenhum tratamento científico, como reportagens de jornais, revistas, cartas, fotografias, normas jurídicas, entre outros meios de coleta de informação. É importante ressaltar que esse método 
se diferencia da pesquisa bibliográfica, pois esta última refere-se à utilização de informações já trabalhadas por outros autores, ou seja, quando é realizado um tratamento científico prévio.

Nesse sentido, foram averiguadas durante a análise documental, as principais leis brasileiras relacionadas às áreas protegidas, que são: a Lei n ${ }^{\circ}$ 4.771, de 15 de dezembro de 1965, que instituiu o Novo Código Florestal; a Lei no 7.803, de 18 de julho de 1989, que alterou a redação da Lei $n^{\circ}$ 4.771/65; a Lei $n^{\circ} 12.651$, de 25 de maio de 2012, que dispõe sobre a proteção da vegetação nativa e revoga as Leis $n^{\circ}$ 4.771/65 e 7.754/89; a Lei $n^{\circ}$ 9.985, de 18 de julho de 2000, que instituiu o Sistema Nacional de Unidade de Conservação da Natureza (SNUC) e o Decreto $\mathrm{n}^{\circ}$ 5.758, de 13 de abril de 2006, que instituiu o Plano Estratégico Nacional de Áreas Protegidas (PNAP). Ademais, foram realizadas pesquisas na Constituição da República Federativa do Brasil, de 1988, em particular no Capítulo VI desta Constituinte, intitulado "Do Meio Ambiente".

O trabalho de realizar uma análise documental, entretanto, não revoga a necessidade da realização de uma pesquisa bibliográfica prévia, pois, de acordo com Minayo (1994), esta é indispensável para o andamento do trabalho de pesquisa, já que para a autora, é necessário articular a fundamentação teórica com o objeto a ser pesquisado, de forma a criar uma base teórica para se olhar os dados.

Portanto, a primeira etapa dessa pesquisa constituiu na realização de uma extensa pesquisa bibliográfica, em livros, artigos, periódicos, teses e dissertações. Esta foi efetuada na intenção de realizar um maior aprofundamento sobre a temática pesquisada, e assim articular os conceitos teóricos com as análises oriundas da análise documental.

\section{INCORPORAÇÃO DO CONCEITO DE PARTICIPAÇÃO NA LEGISLAÇÃO BRASILEIRA}

A temática da participação em áreas protegidas segue a tendência dos discursos sobre participação no Estado brasileiro. É possível perceber a gradual expansão dos discursos referentes ao envolvimento da sociedade na gestão de áreas protegidas nos instrumentos legais que foram instituídos no Brasil, principalmente a partir dos anos 60.

Ao analisar o Código Florestal de 1965 (Lei 4.771/65, revogado pela Lei nº 7.803/89 e Lei no 12.651/12), é possível observar a temática da participação em alguns artigos. Como no art. $16^{\circ}$, que versa sobre a instituição de florestas de domínio privado. Nesse sentido, é conferido ao proprietário da terra à responsabilidade de proteger os recursos florestais existentes em sua propriedade. Desse modo, o Código Florestal de 1965 confia à população o compromisso de proteger os recursos naturais e a biodiversidade em consonância com o Estado.

Ademais, é possível observar ao analisar o Código Florestal de 1965, que existe certa preocupação com as particularidades das populações onde as florestas são instituídas. No art. $27^{\circ}$, o qual discorre sobre a proibição do uso de fogo nas florestas e demais formas de vegetação, o artigo forja um precedente expresso em seu parágrafo único: "se as peculiaridades locais ou regionais justificarem o emprego do fogo em práticas agropastoris ou 
florestais, a permissão será estabelecida por ato do Poder Público, circunscrevendo as áreas e estabelecendo normas de precaução".

Nos artigos $42^{\circ}$ e $43^{\circ}$ pode-se notar a preocupação com a conscientização da população, já que estes discorrem sobre a inclusão de textos sobre educação florestal nos livros escolares, sobre a adição obrigatória de programas e dispositivos de interesse florestal nas estações de rádio e televisão e sobre a obrigatoriedade de se instituir a semana florestal nas escolas e em estabelecimentos públicos.

Portanto, a análise do Código Florestal de 1965 revela a existência de uma preocupação com o caráter partilhado sobre as responsabilidades de proteção da natureza. No entanto, é importante ressaltar que esta proteção apesar de compartilhada, possui cunho autoritário, pois é realizada de maneira compulsória. O indivíduo divide a obrigação da conservação, mas não é conferida a sociedade a capacidade de decidir. A participação está estabelecida no nível de auxílio ao Estado e no nível da conscientização da população, caráter esse que se enquadra no entendimento de participação disseminado nas décadas de 1960 e 1970, onde o diálogo não é contemplado e as decisões não são partilhadas com a sociedade.

Vinte e dois anos após a implementação do Código Florestal de 1965, institui-se em 1988 a nova Constituição da República Federativa do Brasil. Essa constituição é marcada pelo restabelecimento de práticas democráticas, por abordar a questão da participação e ainda por tratar a respeito da participação da sociedade na proteção da natureza (DAGNINO, 2002; LAVALLE, 2011; AVRITZER, 2011).

A Constituição de 1988 concede ao indivíduo o direito de participar da política para além do exercício do voto e, no texto da Constituinte é inserido o estabelecimento de instituições participativas, em particular os conselhos. Este fato que aponta para a ampliação da participação da população.

Após o estabelecimento da Constituição de 1988, é instituída a Lei 7.803/1989, que altera a redação da Lei 4.771/65, que instituiu o Código Florestal. Entre outras determinações a Lei 7.803/89 apresenta a categoria de Reserva Legal. A Reserva Legal é definida no art. $1^{\circ}$ dessa Lei como sendo uma "área localizada no interior de uma propriedade ou posse rural, excetuada a de preservação permanente, necessária ao uso sustentável dos recursos naturais, à conservação e reabilitação dos processos ecológicos, à conservação da biodiversidade e ao abrigo e proteção de fauna e flora nativas" (BRASIL, 1965). Nesse sentido, são os proprietários que realizam a manutenção da Reserva Legal, o que caracteriza o compartilhamento da responsabilidade de proteção entre o poder público e a sociedade.

Assim, é possível vislumbrar que a inclusão da sociedade já é cogitada nesse documento, desde a sua criação em 1968, incluindo as posteriores alterações realizadas em 1989, porém a noção de inclusão social é realizada de maneira sutil. Na Lei no 7.803/89, ainda não é possível notar a preocupação em instaurar equidade de decisão política, social e econômica, a sociedade não é cogitada como ativamente participante do processo de gestão.

Apesar do Código Florestal inserir a questão do envolvimento social na proteção da natureza, a radicalização da noção de participação, no sentido de inserir a população em um 
processo coletivo de negociação e decisão, além da corresponsabilidade entre sociedade e poder público, é evidenciada de forma mais clara em 2000, a partir do Sistema Nacional de Unidades de Conservação (SNUC, Lei 9.985/00).

A ênfase concedida à participação da sociedade nas estratégias de gestão e a necessidade de se considerar as demandas sociais, culturais e econômicas locais são visualizadas em algumas das diretrizes que regem o SNUC, estipuladas no art. $5^{\circ}$, como é o caso das diretrizes II, III, V, VIII e IX, que estão listadas abaixo:

II - assegurar os mecanismos e procedimentos necessários ao envolvimento da sociedade no estabelecimento e na revisão da política nacional de unidades de conservação;

III - assegurar a participação efetiva das populações locais na criação, implantação e gestão das unidades de conservação;

$\mathrm{V}$ - incentivar as populações locais e as organizações privadas a estabelecerem e administrarem unidades de conservação dentro do sistema nacional;

VIII - assegurar que o processo de criação e a gestão das unidades de conservação sejam feitos de forma integrada com as políticas de administração das terras e águas circundantes, considerando as condições e necessidades sociais e econômicas locais;

IX - considerar as condições e necessidades das populações locais no desenvolvimento e adaptação de métodos e técnicas de uso sustentável dos recursos naturais.

Desse modo, pode-se observar ao analisar as diretrizes que regem o SNUC, que a participação é entendida como um processo ativo de engajamento populacional, que prima pelo compartilhamento das decisões, tanto no ato da criação das Unidades de Conservação quanto na conservação dessas áreas.

Além das diretrizes que guiam o Sistema Nacional de Unidades de Conservação (SNUC), outros artigos dessa mesma lei abordam a questão da participação. $\mathrm{O}$ art. $29^{\circ}$ desse documento prevê a obrigatoriedade do estabelecimento de conselhos consultivos nas unidades de conservação, formados pela organização da sociedade civil.

Seis anos após a criação do SNUC, é aprovado o Decreto no 5.758/06 que institui o Plano Estratégico Nacional de Áreas Protegidas (PNAP) que reafirma e enfatiza o compromisso das áreas protegidas com a inclusão social e a participação. É possível observar nesse documento o aprofundamento da discussão sobre diversos temas relacionados diretamente com a questão da inclusão social. Pela primeira vez em um aparato legal brasileiro há referência sobre a conservação da diversidade cultural, logo, subentende-se que a conservação não está restrita a diversidade biológica. É incluído no PNAP o reconhecimento da necessidade de valorização dos aspectos culturais para a conservação da natureza.

Nesse documento, a participação da sociedade na gestão de Unidades de Conservação não é desconectada da realidade social, econômica e cultural da população local. Parte-se do pressuposto que para exercer de modo eficaz a gestão participativa é necessário considerar os 
aspectos socioeconômicos e culturais da região onde estas áreas estão inseridas. Como é possível observar na VIII diretriz que rege o PNAP:

O planejamento para o estabelecimento de novas unidades de conservação, bem como para a sua gestão especifica e colaborativa com as demais áreas protegidas, deve considerar as interfaces da diversidade biológica com a diversidade sociocultural, os aspectos econômicos (...).

Ao analisar o PNAP, pode-se notar que a participação é entendida como estratégia indispensável para gerar benefícios sociais e econômicos para a população que vive dentro de áreas protegidas e em seu entorno. A temática da participação é amplamente discutida, o PNAP possuiu como um de seus princípios a "promoção da participação, da inclusão social e do exercício da cidadania na gestão de áreas protegidas, buscando permanentemente o desenvolvimento social, especialmente para as populações do interior e do entorno das áreas protegidas" e afirma ter como diretriz o fortalecimento dos "instrumentos existentes de participação e controle social”.

O PNAP é o documento que contempla de maneira mais holística e clara a questão da participação no Brasil. O documento ressalta nas entrelinhas que além de conscientizar e consultar, a participação também abrange o compartilhamento de poder, que para se efetivar a política de proteção da natureza não pode se sobrepor aos interesses locais, que a valorização dos aspectos culturais e sociais das localidades onde se encontram áreas protegidas é também de grande importância para estimular a autoestima da população e ainda salientar formas de participação. De acordo com Irving (2010), os princípios delineados nesse documento:

Trazem a tona e ilustram, neste texto oficial de políticas públicas, uma nova forma de se pensar a proteção da natureza, na qual elementos éticos, culturais e relativos ao compromisso de inclusão social ganham relevância e são expressos como norteadores de movimentos futuros (IRVING, 2010, pg. 139).

Desse modo, pode-se observar que a instituição de práticas participativas, de tal modo que permitam o compartilhamento da tomada de decisões e de poder, é de caráter compulsório nos mais recentes instrumentos legais brasileiros, pois tanto o SNUC quanto o PNAP incluem em seus objetivos, princípios e diretrizes, a discussão sobre a promoção da participação na gestão de áreas protegidas.

A respeito das causas que motivaram a inserção da retórica da participação de maneira mais abrangente é elucidada por Irving (2010, pg. 127), de acordo com a autora: "neste campo de debate e reflexão, a própria noção de conservação da natureza passa a ser também entendida como construção humana, na qual novas lógicas são delineadas, em um esforço de resgate e reintegração entre sociedade e natureza". 


\section{CONCLUSÃO}

Ao tecer esse pequeno histórico sobre a relação das políticas participativas na legislação brasileira referente às áreas protegidas é possível observar que existe uma orientação para se efetivar a corresponsabilidade a respeito da proteção de áreas protegidas entre poder público e sociedade desde a ratificação do Código Florestal de 1965 (Lei n ${ }^{\circ}$ 4.771/65). No entanto, a Lei $n^{\circ} 4.771 / 65$, não estabelece a participação da sociedade em instâncias decisórias, esta Lei possui como foco a participação realizada em formas de auxílio ao Estado.

Com o passar dos anos as discussões tornam-se cada vez mais sólidas e passam a ser embasadas na perspectiva de que a participação é benéfica tanto para a sociedade quanto para as áreas protegidas. Essa tendência de ampliação do discurso em prol da participação da população em áreas protegidas em instâncias decisivas surge a partir da década de 1980 com o advento da Constituição de 1988, e tem seu ápice nos anos 2000. Desse modo, o aparato legal relativo ás áreas protegidas que desponta no início do XXI tem como característica a radicalização do entendimento do conceito de participação.

Nesse sentido, participar não se restringe a auxiliar o estado nas estratégias de proteção da natureza, este conceito assume um caráter emancipatório, ativo e de controle social do aparato estatal. O conceito de participação nos documentos do Sistema Nacional de Unidades de Conservação (SNUC, Lei no 9.985/00) e do Plano Estratégico Nacional de Áreas Protegidas (PNAP, Decreto $n^{\circ}$ 5.758/06) é entendido como expressão do exercício da cidadania, do direito do cidadão decidir sobre as demandas que influenciam seu modo de vida, sua cultura e na sua forma de alcançar seu sustento.

Por fim o estudo das leis relativas às áreas protegidas no Brasil possibilitou a observação de que o entendimento de participação observado nesses documentos acompanham a evolução do discurso político da participação no Brasil, que se iniciou de maneira mais definida nos anos 1960 e evoluiu e ampliou de forma gradativa até o aprimoramento do discurso nos anos 2000.

\section{REFERÊNCIAS BIBLIOGRÁFICAS}

AYRES, H. H. F.; IRVING, M. A. O olhar psicossocial para a gestão participativa de áreas protegidas: refletindo sobre possibilidades e desafios. In: Irving, M.A. (Org.). Áreas Protegidas e Inclusão Social: Construindo Novos Significados. Rio de Janeiro: Fundação Bio-Rio: Núcleo de Produção Editorial Aquarius, 222 p., 2006.

AVRITZER, L. A qualidade da democracia e a questão da efetividade da participação: mapeando o debate. In: Pires, R.R.C. (Org.). Efetividade das instituições participativas no Brasil: estratégias de avaliação. Brasília: Ipea, 372p., 2011.

BRASIL. Lei no 4.771, de 15 de setembro de 1965. Institui o Novo Código Florestal, 1965.

BRASIL. Constituição da República Federativa do Brasil, 1988.

BRASIL. Lei $\mathbf{n}^{\mathbf{0}} \mathbf{7 . 8 0 3}$, de 18 de julho de 1989. Altera a redação da Lei $n^{\circ} 4.771$, de 15 de setembro de 1965, e revoga as Leis $\mathrm{n}^{\circ} 6.535$, de 15 de junho de 1978 , e $\mathrm{n}^{\mathrm{o}} 7.511$, de 7 de julho de 1986. 
BRASIL. Lei $\mathbf{n}^{\mathbf{0}}$ 9.985, de 18 de julho de 2000. Institui o Sistema Nacional de Unidade de Conservação da Natureza, 2000.

BRASIL. Decreto no 5.758, de 13 de abril de 2006. Institui o Plano Estratégico Nacional de Áreas Protegidas - PNAP, seus princípios, diretrizes, objetivos e estratégias, e dá outras providencias, 2006.

BRASIL. Lei $\mathbf{n}^{\mathbf{0}} \mathbf{1 2 . 6 5 1}$, de 25 de maio de 2012. Dispõe sobre a proteção da vegetação nativa; altera as Leis $\mathrm{n}^{\mathrm{os}}$ 6.938, de 31 de agosto de 1981, 9.393, de 19 de dezembro de 1996, e 11.428, de 22 de dezembro de 2006; revoga as Leis $\mathrm{n}^{\mathrm{os}} 4.771$, de 15 de setembro de 1965 , e 7.754, de 14 de abril de 1989, e a Medida Provisória n ${ }^{\circ}$ 2.166-67, de 24 de agosto de 2001; e dá outras providências, 2012.

COMPARATO, F. K. Para viver a democracia. São Paulo: Editora Brasiliense, 214 p. 1989.

DAGNINO, E. Sociedade civil e espaços púbicos no Brasil. In: Dagnino, E. (Org.). Sociedade Civil e espaços públicos no Brasil. São Paulo: Editora Paz e Terra/UNICAMP, 364p. 2002.

DEMO, P. Participação é conquista. São Paulo: Cortez, 176p., 1988.

GOHN, M. G. Conselhos gestores e participação sociopolítica. São Paulo: Cortez, 122p. 2011.

IRVING, M. A.; GIULIANI, G. M.; LOUREIRO, C. F. Natureza e sociedade: desmistificando mitos para a gestão de áreas protegidas. In: Irving, M.A, Loureiro, C.F. \& Giuliani, G. M. (Org.). Parques Estaduais do Rio de Janeiro: construindo novas praticas para a gestão. São Carlos: Editora Rima, 147p., 2008.

IRVING, M. A. Áreas protegidas e inclusão social: uma equação possível em políticas públicas de proteção da natureza no Brasil? Sinais Sociais, 4 (12): 122-147. 2010.

LAVALlE, A. G. Participação: valor, utilidades, efeitos e causa. In: Pires, R.R.C. (Org.). Efetividade das instituições participativas no Brasil: estratégias de avaliação. Brasília: Ipea, 372 p., 2011.

LOUREIRO, C. F. B. Educação Ambiental Transformadora. In: Brasília: Ministério do Meio Ambiente. Identidades da educação ambiental brasileira. Brasília: Edições MMA, 156 p. 2004.

LOUREIRO, C.F.B. Sustentabilidade e Educação: um olhar da ecologia política. São Paulo: Cortez, 128 p., 2012.

MINAYO, M.C.S.. Ciência, técnica e arte: o desafio da pesquisa social. In: Minayo, M.C.S. (Org.). Pesquisa Social: teoria, método e criatividade. Petrópolis: Editora Vozes, 80 p. 1994.

OLIVEIRA, M. M. Como fazer pesquisa qualitativa. Petrópolis: Editora Vozes, 182 p. 2007.

REED, M. S. Stakeholder participation for environmental management: a literature review. Biological Conservation, 4: 2417-2431. 2008.

TULER, S.; WEBLER, T. Voices from the forest: what participants expect of a public participation process. Society \& Natural Resources: An International Journal, 12 (5): 437:453. 1999. 